\title{
El origen de la novela gótica inglesa y su recepción en Francia: análisis traductológico de The Castle of Otranto (1764) de H. Walpole y su primera traducción al francés (1767)
}

\section{(The origin of the English Gothic novel and its reception in France: translation analysis of $H$. Walpole's The Castle of Otranto [1764] and its first translation in French [1767])}

\author{
María del Carmen Moreno Paz \\ I02mopam@uco.es \\ Universidad de Córdoba
}

Fecha de recepción: 14 de abril de 2015

Fecha de aceptación: 11 de mayo de 2015

Resumen: El presente trabajo tiene como principal objetivo el estudio y análisis de la considerada como primera novela gótica en inglés, The Castle of Otranto (1764), de Horace Walpole, y la primera traducción realizada en francés por Marc-Antoine Eidous en 1767 como Le Château d'Otrante, dada la importancia de esta obra como germen de la literatura gótica, que supuso un acercamiento al prerromanticismo y una ruptura con los valores ilustrados del siglo XVIII. Por este motivo, con este estudio pretendemos llevar a cabo un análisis que nos permita establecer conclusiones sobre la adecuación de la traducción en relación con las corrientes literarias y estéticas de la época y la repercusión que tuvo la obra en Francia a finales del siglo XVIII. Para ello, llevaremos a cabo un análisis traductológico según los distintos niveles de lengua: morfosintáctico, léxico-semántico y pragmático-cultural, en los que distinguiremos las principales técnicas de traducción empleadas y los posibles errores cometidos por el traductor.

Palabras clave: Literatura inglesa, Novela gótica, Horace Walpole, Belles infidèles, Análisis traductológico.

Abstract: This paper aims to study and analyse Horace Walpole's The Castle of Otranto (1764), considered to be the first Gothic novel in English, and its first translation in French as Le Château d'Otrante (1767), by MarcAntoine Eidous, given the importance of this work as the origin of Gothic literature, which meant an approach to Romanticism and a break with the 
values of the Enlightenment at $18^{\text {th }}$ century. For this reason, the analysis we intend to accomplish in this study will allow us to draw conclusions about the adequacy of the translation in relation with the literary and aesthetic trends and the impact of the novel in France at the end of $18^{\text {th }}$ century. For this purpose, we will carry out a translation analysis considering the morphosyntactic, lexical-semantic and pragmatic-cultural linguistic levels, which will allow us to distinguish the main translation techniques used, as well as the mistakes made by the translator.

Key words: English literature, Gothic novel, Horace Walpole, Belles infidèles, Translation analysis.

\section{INTRODUCCIÓN}

A pesar de no haber gozado siempre de gran consideración por parte de la crítica, es indudable que la literatura gótica marcó con su aparición en el siglo XVIII un antes y un después en la historia de la literatura. En un periodo marcado por el racionalismo y la corriente ilustrada, el gótico se percibe a menudo como el lado negativo de la modernidad, que surge como oposición a los ideales ilustrados (Luckhurst, 2012: 75). En efecto, el propio término "gótico» con el que se califica a esta corriente novelística tenía en el siglo XVIII connotaciones despectivas (Watt, 1998: 194; Spacks, 2006: 198), pues se utilizaba, con frecuencia, como sinónimo de «bárbaro», usado como epíteto para calificar lo «ignorante» y «supersticioso» (Carson, 2009: 259) ${ }^{1}$.

Sin embargo, no puede obviarse la consideración que establecen algunos autores acerca de que la literatura gótica supone también una recuperación del pasado histórico y literario (Lynch, 2008: 50-51)². De este

\footnotetext{
${ }^{1}$ Desde una perspectiva etimológica e histórica, el término gothic procede en inglés de Goth ('godo'), nombre con el que se denominaba de forma generalizada en el siglo XVIII a los pueblos germánicos que habían acabado con el Imperio Romano en los siglos IV y V y que, de acuerdo con las ideas neoclásicas, habían sumergido al mundo en oscuridad y tiranía durante la Edad Media al destruir la mayor civilización conocida (Punter, 1996: 4-5; Ellis, 2007: 22-23).

El término gothic pasó, por tanto, a calificar a la cultura medieval e incluyó las connotaciones negativas que lo asociaban con lo bárbaro e incivilizado, frente a los valores neoclásicos propugnados por la llustración. De acuerdo con Punter (1996: 5), el término "gótico» pasó de este modo a utilizarse con un sentido opuesto a lo «clásico».

${ }^{2} \mathrm{~A}$ finales del siglo XVII y durante el siglo XVIII el periodo gótico se comenzó a ver también de forma idealizada como una etapa de libertad, en la que los nobles guerreros y virtuosos imponían límites al poder monárquico (Carson, 2009: 259-260). Botting (2008: 5, 41-42) sostiene que, desde el punto de vista histórico, el movimiento gótico puede asociarse con la historia de los pueblos germánicos, cuyos valores de libertad y democracia se consideraban un legado. De este modo, se creía que las beligerantes tribus germánicas (en concreto, los godos) habían acabado con la tiranía del Imperio Romano, que a su vez se identificaba con la Iglesia Católica. Frente a la tiranía y despotismo de la Iglesia Católica de Roma que denunció la Reforma protestante, el término "gótico» se relacionó con una cultura nacional libre, natural y
} 
modo, la novela gótica, inspirada en antiguas leyendas celtas y relatos medievales, recupera un legado perdido $u$ olvidado sobre el nacimiento y consolidación de la nación británica, ya iniciado en el siglo XVI por Spenser y Shakespeare y reanudado a mediados del XVIII por poetas como Thomas Gray y la corriente poética de la Graveyard School, que se aproxima a la sensibilidad prerromántica en su búsqueda de «lo sublime» (Carter y McRae, 2006: 188-189). Así, frente a la belleza armoniosa y proporcionada que propugnaban las corrientes racionalistas y neoclásicas, lo sublime se asocia con la grandiosidad y magnificencia y todo aquello que desafía el conocimiento racional y la comprensión humana, incluido el terror (Botting, 2008: 3-4).

El vínculo entre lo sublime y el terror se aprecia más claramente con la posterior aparición de «lo gótico», una nueva forma de expresión que se plasma a través de la novela y que abarca lo fantástico, lo macabro y lo sobrenatural, sirviéndose de castillos encantados, tumbas y naturaleza salvaje (Carter y McRae, 2006: 189), así como de «elementos desatados o el misterio de lo exótico, lo desconocido e inexplicable» (De la Concha, 1988: 59-60). Por tanto, además de la búsqueda de lo sublime, que en el caso de las novelas góticas persigue un sobrecogimiento más enfocado al terror que al asombro o la fascinación maravillosa, la literatura gótica se caracteriza por la presencia del componente sobrenatural, lo que lleva a clasificar este subgénero dentro de la categoría de literatura fantástica ${ }^{3}$.

En definitiva, nos encontramos ante una corriente que no solo recupera los antiguos relatos medievales y utiliza el pasado medieval para situar sus historias, sino que los transforma en un nuevo género caracterizado por lo sobrenatural, la búsqueda del exceso y la transgresión y la ruptura con los valores sociales y culturales que imperaban a finales del siglo XVIII, ya que se interesa por los objetos y prácticas que se consideran negativos, irracionales, inmorales y fantásticos (Botting, 2008: 2).

Por lo que respecta a su repercusión, a pesar de las duras críticas que recibieron las novelas góticas en su época por parte de la crítica debido

creativa, en contraposición con los modelos clásicos impuestos (Ellis, 2007: 23-24; Botting, 2008: 42). Se produjo, de este modo, una alteración en la consideración de este concepto, que conllevó una revalorización del pasado, que se consideraba, desde un punto de vista nostálgico, superior al presente, y que constituía un legado esencial de la cultura británica.

${ }^{3} \mathrm{Si}$ bien es cierto que esta corriente literaria ha derivado o influido en otros géneros literarios (como la novela policíaca o la novela de terror, así como algunos ejemplos de la novela victoriana inglesa del siglo XIX), la crítica coincide en aplicar este calificativo a las novelas comprendidas entre 1764 y 1820, con la publicación de The Castle of Otranto de Horace Walpole y Melmoth the Wanderer de Charles Maturin, respectivamente. Como señala Punter (1996: 1), aunque las obras comprendidas en este periodo presentan notables diferencias entre sí, se han agrupado en un mismo género debido a las similitudes que comparten: el énfasis en la representación del terror, los escenarios antiguos, la presencia del elemento sobrenatural, la estructura formulaica y los personajes estereotipados. 
al peligro que representaban para la razón y la rectitud moral de sus lectores (Lynch, 2008: 48-49; Luckhurst, 2012: 74-75), debe resaltarse la enorme popularidad de la que gozaron las novelas góticas entre el público lector de la época, hasta el punto de que, en la década de 1790, constituía el género novelístico dominante en el mercado editorial (Punter, 1996: 7-8). En efecto, se trata de una época en la que las clases medias comenzaron a adquirir mayor importancia, disminuyeron los niveles de analfabetismo y la difusión de la cultura aumentó notablemente, lo que contribuyó a la consolidación del género novelístico (Carson, 2009: 262).

La primera novela gótica inglesa (The Castle of Otranto, de Horace Walpole) se tradujo al francés tan solo tres años después de su aparición, en 1767. Sin embargo, de acuerdo con Killen (1984: 75), aunque la literatura gótica llegara a Francia poco después de su aparición en Inglaterra, se trató de un género demasiado novedoso para el público francés, ya que difería notablemente de los relatos medievales de caballería que habían comenzado a resurgir en Francia en esta época, por lo que no fue recibido con tanto entusiasmo y aceptación como en Inglaterra ${ }^{4}$. Habrá que esperar hasta el final de la Revolución francesa para que la novela gótica inglesa irrumpa definitivamente en Francia. Como señalan algunos autores (Killen, 1984: 80; Schneider, 1985: 121-122), además de los escritores franceses que habían contribuido a preparar el terreno, los terribles sucesos acontecidos en la Revolución habían avivado el gusto por los escenarios sangrientos y terribles. Asimismo, la Revolución supuso también la ruptura de las normas clásicas y las tradiciones anteriores, dejando paso libre al sentimiento y a la novedad, así como al fin de la censura en temas religiosos, políticos o morales (Hale, 2008: 69). Por otra parte, la Revolución había obligado al exilio a muchos aristócratas, que emigraron a Inglaterra y tomaron conciencia de la literatura de moda y, en muchos casos, se vieron obligados a realizar traducciones tras arruinarse debido a la Revolución (Prungnaud, 1994: 19).

Como consecuencia de estos factores contextuales, las novelas góticas de Radcliffe y Lewis cautivaron enseguida al público francés a

\footnotetext{
${ }^{4}$ La obra de Clara ReeveThe Old English Baron (1777), traducida al francés nueve años después de su publicación como Le Vieux Baron anglais, ou les Revenants vengés, tampoco gozó de gran éxito en Francia. Sin embargo, según Killen (1984: 78-80), la publicación de relatos antiguos de caballería en la colección literaria Bibliothèque universelle des Romans (1772-1789) preparan el terreno y siembran el gusto por lo gótico y sobrenatural de forma progresiva, a lo que contribuyen novelas sentimentales francesas como Adèle y Théodore (1782) de $\mathrm{M}^{\mathrm{me}}$ de Genlis y el gusto por lo misterioso y subterráneo en diversas obras de teatro. Asimismo, entre 1778 y 1796 se publican otras seis traducciones de novelas góticas inglesas, que van calando poco a poco en Francia (Hale, 2008: 71).
} 
finales del siglo XVIII (Killen, 1984: 80-81) ${ }^{5}$. Ante el éxito de estas novelas, que estaban ya tan en boga como en Inglaterra, los traductores franceses se afanaron por traducir nuevas novelas, permitiéndose grandes libertades al introducir los cambios en los textos originales que consideraban necesarios y adaptándolas al gusto francés, pues la tradición de la época en lo concerniente a la traducción se ajustaba a la corriente de las belles infidèles (Prungnaud, 1994: 21) . $^{6}$

En este sentido, teniendo en cuenta no solo la importancia que tuvo el género gótico en su ruptura con los valores ilustrados y su acercamiento al prerromanticismo, sino también la notable repercusión de la que gozó en el siglo XVIII tanto en Inglaterra como posteriormente en Francia, en este trabajo nos centraremos en el análisis contrastivo de la considerada como primera novela gótica, The Castle of Otranto (1764), escrita por Horace Walpole, y su primera traducción al francés, realizada por Marc-Antoine Eidous tan solo tres años más tarde, en 1767, con el título: Le Château d'Otrante. El motivo de esta selección textual reside en la importancia de esta obra como germen de la posteriormente denominada literatura gótica que, a pesar de no gozar de un gran prestigio entre la crítica literaria, fue el origen de otras novelas más destacadas de esta corriente, como The Mysteries of Udolpho, de Ann Radcliffe (1794), The Monk, de Matthew Lewis (1796) o Frankenstein, or the Modern Prometheus, de Mary Shelley (1818), por citar algunos ejemplos.

Por este motivo, y sirviéndonos del texto correspondiente a la primera novela gótica y su primera traducción al francés, pretendemos llevar a cabo un análisis traductológico de carácter descriptivo en el que se tengan en cuenta las características textuales de ambas obras, el método de traducción, las técnicas de traducción empleadas y los errores cometidos en

\footnotetext{
${ }^{5}$ En 1797, se tradujeron The Mysteries of Udolpho (tres años después de su publicación) y The Italian (en el mismo año de su publicación en Inglaterra, con dos traducciones diferentes al francés). En este mismo año, se publicó también la traducción al francés de The Monk de M. Lewis, tan solo un año después de su aparición, que cosechó incluso más éxito en Francia que en Inglaterra debido al anticlericalismo que surgió tras la Revolución. Del mismo modo, las novelas de gótico racional (o sobrenatural explicado) de Ann Radcliffe gustaron más al público francés que otras de corte más fantástico como la de Horace Walpole, debido al racionalismo aún imperante (Prungnaud, 1994: 21).

${ }^{6}$ Esta corriente se basa en una metodología de traducción que se caracterizaba por su falta de fidelidad al texto original, a menudo recurriendo a la adaptación o, incluso, a la reescritura. De este modo, el traductor se tomaba grandes libertades al trasvasar el texto original, en ocasiones incluso cambiando el título a las obras o eliminando pasajes enteros (Prungnaud, 1994: 21-23). El traductor se convierte así en un corrector y censurador del texto, que a menudo lleva a cabo modificaciones innecesarias en aras de la estética literaria para complacer a sus lectores y afrancesar el texto, guiándose por sus propios criterios y valores socioculturales y adaptando y «embelleciendo» la obra original para acomodarla al buen gusto francés (Alberdi y Arregui, 2009: 110).
} 
el texto meta, de modo que podamos extraer conclusiones sobre la calidad y adecuación de la obra traducida al francés y su relación con la recepción de dicha obra en la cultura de llegada, así como sobre las corrientes de traducción imperantes en la segunda mitad del siglo XVIII.

\section{El origen de la novela gótica: the Castle of Otranto (1764) de HORACE WALPOLE}

Una vez expuestas las características generales que definen la corriente de la literatura gótica y delimitado el contexto en el que surge y se desarrolla, nos centraremos de forma más específica en la novela objeto de nuestro análisis, The Castle of Otranto. No obstante, antes de esbozar las características narrativas y los rasgos discursivos y lingüísticos que presenta, creemos conveniente dedicar unas líneas a su autor.

La figura de Horace Walpole ha estado durante mucho tiempo sujeta a la desaprobación y la crítica, como sugiere su biógrafo Ketton-Cremer (1946: 17), del mismo modo que ocurría con la propia novela gótica. No obstante, gracias a las teorías sobre crítica literaria del siglo XX, en las que se otorga mayor relevancia a la corriente gótica, el creador del género ha pasado a gozar de una mayor consideración.

Nacido en 1717, Horace Walpole fue hijo del político Sir Robert Walpole, considerado como la primera persona en ostentar el cargo de primer ministro en Gran Bretaña tras el ascenso del rey Jorge I. Miembro del Parlamento británico desde 1741 en el partido liberal de los whigs, Horace Walpole fue un aristócrata aficionado a las antigüedades, la historia y la escritura (Ketton-Cremer, 1946: 78-85) ${ }^{7}$.

\footnotetext{
${ }^{7}$ Aunque no se dedicó a la escritura con asiduidad, pueden mencionarse algunas aportaciones como Epistle from Florence to Thomas Ashton, Esq., Tutor to the Earl of Plymouth, su primer poema formal, que Ketton-Cremer (1946: 60) describe como «an exercise in English history from the Whig point of view», escrito entre 1739 y 1741 . Entre 1742 y 1743 , escribió Sermon on Painting y Aedes Walpolianae, obras sobre pintura y crítica del arte, y una larga sátira sobre algunos políticos contemporáneos, titulada Patapan, or the Little White Dog (Ketton-Cremer, 1946: 87), así como The Beauties, poema en forma de epístola, que se publicó en 1746 con notable éxito (Ketton-Cremer, 1946: 102-107). Otra de sus obras más reconocidas es Anecdotes of Painting in England (1762), escrita a partir de las notas manuscritas del popular grabador George Vertue, con la que contribuyó notablemente al conocimiento sobre la pintura inglesa de los siglos XVI y XVII, a pesar de tratarse de una lectura poco objetiva y con énfasis en lo anecdótico (Ketton-Cremer, 1946: 181-184). Asimismo, puede señalarse The Mysterious Mother, tragedia sobre el polémico tema del incesto que lleva a cabo en 1768 tras abandonar su asiento en el Parlamento, oHistoric Doubts on the Life and Reign of King Richard the Third, que defiende el trato injustificado que había recibido la figura de Ricardo III por parte de los historiadores, y que resultó ser un éxito, a pesar de estar escrita por un inexperto en historia (Ketton-Cremer, 1946: 247-251).Su última obra, antes de morir en 1796, se titula Reminiscences, written in 1788, for the amusements of Miss Mary and Miss Agnes Berry formada por nueve capítulos sobre anécdotas acerca de Jorge I y Jorge II (Ketton-Cremer 1946: 291, 300-303).
} 
Además de su obra The Castle of Otranto, que inauguró el género de la novela gótica, su mayor aportación a la historia y la literatura reside en la correspondencia que mantuvo a lo largo de su vida con diferentes personajes. De acuerdo con Kettom-Cremer (1946: 113-118), Walpole estaba decidido a convertirse en cronista de su época para la posteridad, a través de la abundante correspondencia que mantenía con diversas amistades, que escogía con sumo cuidado, de modo que pudiera tratar temas diferentes con cada uno de ellos. Así, mientras que con Horace Mann trataba cuestiones políticas, la correspondencia con George Montagu discurría en torno a las anécdotas de la sociedad y otras trivialidades; con Thomas Gray discutía sobre literatura, y con William Cole, sobre su pasión por las antigüedades y las colecciones.

La adquisición en 1747 de una casa en Twickhenman, a las afueras de Londres, actualmente conocida como Strawberry Hill (donde creó su propia imprenta en 1757), marcó un punto de inflexión en la vida de Walpole, pues su construcción y decoración con estilo gótico se convirtieron en su pasión central, a pesar de que siguió cultivando sus otros intereses (Ketton-Cremer, 1946: 108-109).Fue en esta casa donde Walpole escribió su obra más conocida, que surgió a raíz de una pesadilla del autor en 1764. Preocupado por la recepción que pudiera tener la obra, ya que era miembro del Parlamento, Walpole decidió publicarla de forma anónima, como una traducción de un manuscrito antiguo, con el título The Castle of Otranto, a Story. Translated by William Marshal, Gent. From the Original Italian of Onuphrio Muralto, Canon of the Church of St. Nicholas at Otranto. A pesar de su preocupación, sin embargo, la novela fue muy bien acogida por el público, por lo que Walpole publicó una segunda edición en 1765, identificándose como el verdadero autor y explicando las razones que lo habían llevado a presentar la obra como una traducción, y añadiendo el término gothic en el subtítulo (Ketton-Cremer, 1946: 194-195).

Por lo que respecta de forma más específica a la macroestructura de la novela que pretendemos analizar, se encuentra estructurada en cinco capítulos, en los que la acción se desarrolla de forma lineal y lógica, aunque el tiempo interno del relato no se especifica. En cuanto al escenario espacio-temporal, el relato se sitúa en el principado de Otranto, en el reino de Nápoles (Italia) ${ }^{8}$, en algún momento durante las Cruzadas, aunque las coordenadas temporales precisas no se especifican. Asimismo, la acción tiene lugar entre el castillo, el convento y el bosque, por lo que tanto el escenario restringido como la estructura secuencial en cinco capítulos del relato presentan similitudes con las tragedias de Shakespeare,

${ }^{8}$ De acuerdo con Ketton-Cremer (1946: 189-190), Walpole escogió este lugar porque el nombre de la zona le pareció adecuado para su obra, sin saber que existía un verdadero castillo en Otranto. 
especialmente en lo que concierne a su intento de incluir las pasiones exacerbadas, situaciones elementales y técnicas poéticas elaboradas propias del drama isabelino (Ellis 2007: 31).

Aunque se trata de una obra cuya concepción surgió de forma fortuita a raíz de una pesadilla que tuvo Horace Walpole en junio de 1764 y que culminó con la redacción de la novela en el breve periodo de tiempo de dos meses (concretamente, la obra fue acabada el 6 de agosto de 1764), Ketton-Cremer (1946: 191) sostiene que se trata de un trabajo creado con destreza y que conserva fielmente las unidades dramáticas, cuyo desarrollo no queda interrumpido por digresiones o paréntesis en la narración. De acuerdo con Punter (1996: 44), lo verdaderamente destacable de The Castle of Otranto es que supone la recuperación de los antiguos romances épicos y de las anteriores tradiciones literarias que se habían visto suplantadas por la novela. En efecto, en el prólogo a la segunda edición, Walpole manifiesta que su obra The Castle of Otranto constituye un intento de combinar "the two kinds of romance, the ancient and the modern». Su biógrafo Ketton-Cremer (1946: 191-192) sostiene que, aunque Walpole no acierta al mezclar prodigios sobrenaturales con el barbarismo medieval y la cortesía de su propia época, las partes puramente góticas del libro, como la recreación de la atmósfera terrorífica y tenebrosa y los presagios sobrenaturales, resultan más efectivos. Asimismo, Watt (1998: 199) señala que Walpole también es precursor en la caracterización del villano (que él considera héroe a su vez, pues es el verdadero protagonista), ya que, a pesar de tratarse de un tirano cruel y malvado, en ocasiones provoca empatía en el receptor.

En definitiva, esta obra supone una ruptura con la novela realista que imperaba en el siglo XVIII y las corrientes intelectuales racionalistas de la época, así como un acercamiento al estilo prerromántico, en la que el autor da rienda suelta a su imaginación y a su afición por el medievalismo gótico ${ }^{9}$.

\footnotetext{
${ }^{9}$ A pesar de que algunos críticos literarios de la época denunciaron la falta de rectitud moral y consideraron que se trataba de una novela absurda (Botting, 2008: 51), la revelación de la autoría en 1765 no disminuyó el éxito de la novela que, de acuerdo con Spacks (2006: 191), tuvo once ediciones en inglés en el siglo XVIII y, según recoge Punter (1996: 44), en la actualidad cuenta con más de 115 ediciones desde su aparición. Ellis (2007: 27) puntualiza que, aunque la obra tuvo un éxito considerable tras su publicación en 1764 y 1765, sobre todo entre aristócratas y personajes ilustres del círculo de Walpole, su verdadero éxito entre un público más general llegaría veinte o treinta años después, en la década de 1790 (gracias al éxito de las obras de Radcliffe y Lewis), en la que se publicarían nueve ediciones (frente a las dos que hasta entonces se habían publicado en 1764 y 1765), más una veintena de ediciones en el siglo XIX (Killen, 1984: 10). Asimismo, la obra incluso fue adaptada en 1781 al teatro por Robert Jephson con el título The Count of Narbonne, con el agrado y aprobación de Horace Walpole (Ketton-Cremer, 1946: 290).
} 


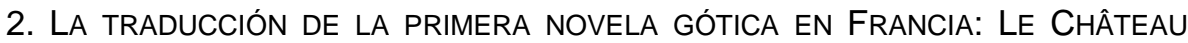
D'OTRANTE DE MARC ANTOINE EIDOUS (1767)

La obra The Castle of Otranto fue traducida en Francia por MarcAntoine Eidous tan solo tres años después de su aparición en Inglaterra, impresa en Ámsterdam y publicada en París por Prault en 1767, con el título Le Château d'Otrante a partir de la segunda edición inglesa, en la que Walpole reconocía su autoría. Sin embargo, Walpole consideró que esta traducción era de mala de calidad (Killen, 1984: 74). No obstante, a diferencia de Inglaterra, en donde se reeditó en múltiples ocasiones, en Francia solo se publicaron cuatro reediciones en el siglo XVIII ${ }^{10}$.Por otra parte, según Prungnaud (1994: 21), entre los siglos XVIII y XIX solo se publicaron cuatro reediciones de la obra, frente a las veinticinco de The Monk, de Matthew Lewis. De acuerdo con la autora, la diferencia en el éxito de la obra en ambos países (y en comparación con el éxito que tuvieron en Francia las obras de Radcliffe o Lewis) se debe a que la obra de Walpole se consideró demasiado fantasiosa e incluso desconcertante por el público francés de la época.

Por lo que respecta al responsable de la traducción, Marc-Antoine Eidous, era un marsellés que sirvió como ingeniero en la Armada española. Cuando regresó a Francia en la década de 1740, se dedicó a la literatura y es conocido por sus más de cuarenta traducciones del latín, inglés y español ${ }^{11}$. Según se indica en la Biographie universelle de los hermanos Michaud (1855: 324), se trataba de un «traducteur infatigable, mais souvent peu exact et surtout peu élégant» ${ }^{12}$. Asimismo, fue autor de aproximadamente 450 entradas en L'Encyclopédie de Diderot y D'Alembert en los primeros cinco volúmenes, sobre cuestiones relacionadas con la heráldica, la herrería y la doma de caballos (Kafker, 1989: 139).

Por otra parte, en lo que a la traducción de The Castle of Otranto se refiere, la traducción se encuentra dividida en dos partes: la primera parte comprende la traducción del prefacio de la segunda edición y los dos primeros capítulos, mientras que la última parte incluye los tres capítulos

\footnotetext{
${ }^{10}$ La primera edición pasó casi desapercibida en Francia, debido, según Killen (1984: 75-77), a que el público francés no estaba preparado para un género tan novedoso. La segunda reedición de la obra tuvo lugar en 1774 y recibió duras críticas de L'Année littéraire (Killen, 1984: 77). Sin embargo, en la década de 1790, y debido al éxito en Francia de las novelas de Radcliffe y Lewis, se volvió a traducir la obra en 1797 con el título Isabelle et Théodore y se publicó por Lepetit en París. Finalmente, en 1798, se publicó en París una nueva versión de la traducción de Eidous con ilustraciones.

${ }^{11}$ Algunas de sus obras traducidas son el Dictionnaire universel de médecine, de Robert James (en el que colaboró con Diderot y otros autores); Histoire de la poésie, de John Brown; Métaphysique de l'âme, ou Théorie des sentiments moraux, de Adam Smith; o Agriculture complète, ou l'Art d'améliorer les terres, de John Mortimer, entre otras.

12 «[Eidous era un] traductor infatigable, aunque con frecuencia era poco exacto y, sobre todo, poco elegante» (la traducción es nuestra).
} 
restantes. Sin embargo, no se ofrece la traducción del prefacio a la primera edición de la obra original, ni tampoco existe un prólogo del traductor ni notas escritas por él. En el siguiente apartado, no obstante, profundizaremos en los rasgos discursivos y lingüísticos de texto original y abordaremos el análisis traductológico de la versión al francés de Eidous.

\section{ANÁLISIS TRADUCTOLÓGICO DE LA OBRA}

\subsection{Metodología de análisis}

Una vez esbozados los rasgos principales de The Castle of Otranto y la traducción al francés de M. A. Eidous como Le Château d'Otrante, el análisis traductológico de ambos textos pretende destacar las características más reseñables que resultan de la contrastación entre estas dos obras, tanto a nivel macrotextual como microtextual, de modo que podamos establecer conclusiones acerca de la traducción como producto final en comparación con el texto original, así como sobre la adecuación de las decisiones adoptadas por el traductor o los posibles errores que se encuentren.

Para este análisis, se ha escogido la primera traducción al francés realizada por M. A. Eidous en 1767 a partir de la segunda edición de The Castle of Otranto $^{13}$. Sin embargo, antes de proceder al análisis comparativo del texto original en inglés y su traducción al francés, dedicaremos un breve apartado a esbozar los rasgos discursivos y lingüísticos del texto original y el texto meta, así como aquellos rasgos formales y ortotipográficos que consideremos relevantes.

En lo que concierne al análisis traductológico, se realizará teniendo en cuenta el nivel morfosintáctico, léxico-semántico y pragmático-cultural y recogiendo las principales semejanzas o diferencias que se encuentren entre original y traducción, adoptando un punto de vista descriptivo y comparativo. Para ello, se señalarán las técnicas de traducción empleadas, siguiendo fundamentalmente la clasificación propuesta por Hurtado Albir (2011: 268-271). Asimismo, se mencionarán los principales errores encontrados en la traducción al francés y, para su categorización, nos basaremos en la propuesta de clasificación de errores de Delisle (recogidos en Hurtado Albir, 2011: 291). Por último, se valorarán algunas nociones

\footnotetext{
${ }^{13}$ No obstante, por lo que respecta al texto original en inglés, y debido a la imposibilidad de acceder a la segunda edición, nos basaremos en la tercera edición de 1766 publicada por William Bathoe en Strand (Londres), cuya única diferencia con respecto a la segunda edición es la inclusión de los dos prólogos correspondientes a la primera y segunda edición. Por tanto, y dado que la traducción al francés se realizó a partir de la segunda edición, solo analizaremos el segundo prefacio. En cuanto a la edición de la traducción al francés, se ha utilizado la primera edición, publicada en 1767, localizada en la Biblioteca de la Universidad de Lovaina.
} 
derivadas del análisis traductológico como el método traductor empleado (Hurtado Albir, 2011: 251-253) o la adecuación y equivalencia del texto meta en los distintos niveles, de modo que nos permita determinar las conclusiones sobre la calidad de la traducción llevada a cabo en francés.

\subsection{Análisis contrastivo inglés-francés}

Por lo que respecta a las características lingüísticas y discursivas del texto original, en primer lugar, cabe destacar el uso de arcaísmos, como nay ('no'), alas (interjección que se utiliza para expresar dolor, pena o preocupación, similar a «jay!» en español), aught (en lugar de 'anything') o ere (con el significado de 'before'), por citar tan solo algunos ejemplos.

Por otro lado, los arcaísmos también se manifiestan en los pronombres de segunda persona. De este modo, se utiliza thou o ye como pronombre personal sujeto singular y plural, respectivamente, en lugar de you; el pronombre personal objeto thee en lugar de you, o el posesivo thy en lugar de la forma que se usa actualmente (your). Asimismo, pueden encontrarse contracciones como 'tis, en lugar de it's, o formas verbales cuya ortografía ha experimentado cambios como consecuencia de la variación diacrónica. Así, se encuentran formas verbales terminadas en -st para la segunda persona del singular del presente, como en sayest, dost, hast o darest (en lugar de say, do, have o dare) o para el pasado, como en sawest, camest, wast o hadst (actualmente, escritas como saw, came, was o had).

Por otra parte, pueden señalarse otros cambios en la morfología de algunas palabras, como la terminación -ck en adjetivos que, en la actualidad, terminan en $-c$, como frantick, o variaciones vocálicas en palabras como chearful (en lugar de cheerful), o intitled (en lugar de entitled). Asimismo, se observan palabras compuestas separadas (con guión o con espacio) que, en la actualidad, se escriben como una sola, como grave-diggers, birth-day, to-day, to-morrow, no where o mean time.

Finalmente, con respecto a la ortotipografía, el texto original se caracteriza también por el empleo de grafías que han caído en desuso en la actualidad. Así, se puede observar el uso de la letra $\Gamma$ (también denominada long s), que se utilizaba en lugar de s en posición inicial o intermedia en una palabra (nunca al final, donde sí se empleaba la grafía s) y que dejó de utilizarse poco antes del siglo $\mathrm{XIX}^{14}$. Asimismo, se observan ligaduras (en inglés, ligatures), es decir, uniones de dos grafemas, en la escritura de algunos caracteres como ct (para la unión de las grafías $c$ y $t$ ), por ejemplo.

En resumen, y antes de pasar al análisis traductológico, el texto original se caracteriza por el empleo de un estilo arcaico, debido,

\footnotetext{
${ }^{14}$ Según se señala en el British and World English Dictionary de Oxford, disponible en su página web de Oxford Dictionaries, cuyo enlace es el siguiente:

http://www.oxforddictionaries.com/definition/english/long-s
} 
principalmente, a la variación diacrónica de la lengua y los cambios producidos en esta desde la época de su escritura, en 1764, hasta la actualidad, si bien el autor intenta también recrear un estilo literario y arcaico para ambientar su obra en una época remota, sobre todo en las intervenciones de los personajes.

Asimismo, la traducción al francés de 1767 presenta rasgos lingüísticos reseñables con respecto a la variación diacrónica de la lengua. De este modo, se observa, por ejemplo, que las desinencias verbales que contienen las vocales - $a i-$ aparecen con el conjunto vocálico -oi- en su lugar. Es el caso de infinitivos como connaître o paraître, que figuran como connoître y paroître; pretéritos imperfectos como avait o était, que aparecen como avoit y étoit; futuros simples como pardonneroit, en lugar de pardonnerait; o condicionales presentes como répondroit, en vez de répondrait, por ejemplo.

Por otra parte, también pueden señalarse otros cambios en la morfología de algunas palabras, como es el caso de aquellas que terminan actualmente en $-n t$, muchas de las cuales figuran en el texto meta terminadas en $-n$. Así, por ejemplo, se observan participios presentes como surprenan (en lugar de surprenant) y sustantivos como raisonnemens (en lugar de raisonnements), enfans (enfants) o sentimens (sentiments). Asimismo, se observan palabras compuestas separadas (con guión o con espacio) que, en la actualidad, se escriben como una sola, como par-tout o bien venu.

Por lo que respecta a la ortotipografía, el texto meta se caracteriza también por el empleo de grafías que han dejado de utilizarse en la actualidad. Así, al igual que en el texto original, se puede observar el uso de la letra $\Gamma$ (también denominada long $s$ ), en lugar de la letra $s$ en posición inicial o intermedia en una palabra. Por otra parte, se observan también las mismas ligaduras que en el texto original, como ct para la unión de las grafías $c$ y $t$, por ejemplo. Además, se emplea siempre el signo \& en lugar de la conjunción copulativa et. Por último, y del mismo modo que ocurría con el texto original, debe mencionarse que las intervenciones de los personajes no se indican con ningún tipo de marca tipográfica.

Por lo tanto, el texto meta se caracteriza también por el empleo de un estilo arcaico, debido, principalmente, a la variación diacrónica de la lengua, ya que el texto data de 1767. Sin embargo, este estilo arcaico resulta más evidente en el texto original, ya que estos arcaísmos se producen no solo en el nivel morfosintáctico y ortotipográfico, sino también en el nivel léxico, lo cual no implica que no se encuentren palabras caídas en desuso en la traducción al francés.

En los siguientes apartados, no obstante, nos centraremos de forma más específica en el análisis traductológico propiamente dicho, 
mencionando las principales técnicas y errores de traducción que afectan a los niveles morfosintáctico, léxico-semántico y pragmático-cultural.

\subsubsection{Nivel morfosintáctico}

Por lo que respecta al nivel morfosintáctico, cabe destacar, por su frecuencia de aparición, la técnica de traducción de ampliación lingüística, que consiste, de acuerdo con Hurtado Albir (2011: 269), en añadir elementos lingüísticos. De este modo, habitualmente se expresa con un mayor número de palabras lo que podría exponerse de modo más conciso, pero sin alterar el sentido del texto original, como ocurre en el siguiente fragmento, al traducir your brother's tutor («el preceptor de vuestro hermano») como qui étoit chargé de l'éducation de votre frère (“[el] que estaba encargado de la educación de vuestro hermano») ${ }^{15}$ :

Nobody has dared to lie there, anfwered Bianca, fince the great aftrologer that was your brother's tutor, drowned himfelf [p. 52-53]

Perslonne n'ole plus y coucher, lui dit Blanche, depuis que l'Aftrologue qui étoit chargé de l'éducation de votre frère s'elt noyé [p. $61(\mathrm{I})^{16}$ ]

En otros casos, sin embargo, además de añadir más elementos lingüísticos, se introducen también precisiones de información que no se incluyen en el texto original, aunque sin alterar significativamente el texto meta, por lo que se asemeja también a la técnica de amplificación:

The Lady Ifabella — what of her! interrupted Manfred eagerly — is at St. Nichola's altar, replied Jerome [p. 64]

La Princelfe Ilabelle... Qu'y a a-t-il? lui demanda Manfred avec précipitation, \& lans lui donner le temps d'achever... s'elt refugiée à l'Autel de Saint Nicolas, reprit Jérôme [p. 74 (I)]

Asimismo, dentro del nivel morfosintáctico, puede señalarse el empleo de otras técnicas como la transposición o cambio de categoría gramatical. Así, por ejemplo, en el siguiente fragmento, el adverbio disconsolately («desconsoladamente») se traduce en francés por un sintagma preposicional: dans une affliction extrême («con una aflicción extrema»). Del mismo modo, el adjetivo uncertain («inseguro», «dudoso»)

\footnotetext{
${ }^{15}$ En este fragmento, y en los próximos que se incluyan, se mantendrá la ortografía utilizada tanto en la versión original como en el texto traducido de 1767.

${ }^{16}$ El número romano que se incluye entre paréntesis en los fragmentos pertenecientes al texto meta alude a la parte en que se encuentra, pues la obra en francés se encuentra dividida en dos partes y la segunda comienza a paginarse desde el principio.
} 
se traduce por un verbo precedido de una preposición: sans savoir («sin saber»):

He returned difconfolately to the monaftery, uncertain on what conduct to refolve [p. 94]

II retourna donc au Monaftère dans une afflicttion extrême, fans favoir à quoi Ie determiner [p. 13 (II)]

En relación también con la transposición, puede señalarse el uso de la modulación estructural o sintáctica, que consiste en efectuar un cambio de punto de vista en la oración a través de la sintaxis, de modo que el texto resulte más natural en la lengua de Ilegada. En el siguiente extracto del prefacio, por ejemplo, se transforma una oración pasiva en activa al cambiar el complemento agente por el sujeto:

The favourable manner in which this little piece has been received by the public, calls upon the author to explain the grounds on which he compofed it. [Preface, p. XIII]

Le Public a fait un accueil fi favorable à cet Ouvrage, que l'Auteur ne peut le difpenler de l'inftruire des motifs qui l'ont porté à le compoler. [Préface, p. V]

En definitiva, las técnicas empleadas en el nivel morfosintáctico revelan la búsqueda de naturalidad en la lengua de llegada, si bien pueden señalarse también algunos errores que afectan a este nivel. En la obra original, el autor recrea un estilo arcaico cuando intervienen los personajes, mediante el uso de pronombres como thou o thee o el empleo de formas verbales antiguas como sayest (en lugar de say), por ejemplo. En la traducción al francés, sin embargo, se pierde con frecuencia este efecto estilístico. Teniendo en cuenta que el error de omisión no solo afecta a la supresión de elementos de información (como ocurre también en el siguiente fragmento al omitirse el inciso starting from his trance in a tempest of rage: «despertándose de su trance en un arrebato de rabia») sino también a la ausencia de determinados efectos estilísticos, hemos considerado que se trata de un error de omisión, ya que en el texto original se recrea un estilo arcaizante y literario que no resulta tan evidente en el texto meta:

Villain! What layeft thou! cried Manfred, starting from his trance in a tempeft of rage, and leizing the Young man by the collar; how dareft thou utter fuch trealon? Thy life fhall pay for it [p. 8-9] 
Que dis-tu là, maraud? s'écria Manfred, en le prenant au collet: comment oles-tu parler de la lorte? Ta vie me répondra de ton infolence [p. 9 (I)]

Además de la omisión de efectos estilísticos, también pueden señalarse algunos errores de sentido como en el siguiente fragmento, en que se traduce incorrectamente el pronombre personal, incurriendo en un contrasentido:

[...] but the Monks could lend him no lights to guels at the route $\underline{\text { The }}$ had taken [p. 118].

[...] mais les Religieux ne purent lui dire la route qu'il avoit prife [p. 41

(II)]

Finalmente, cabe mencionar también otras alteraciones del texto original que pueden considerarse como errores de hipertraducción. En el siguiente fragmento, por ejemplo, el traductor opta por convertir parte del texto en estilo directo, es decir, pone en boca del personaje palabras que, en el texto original, se relatan con un estilo indirecto. Consideramos que, aunque no se altera el sentido del texto original, se trata de un cambio innecesario y responde a la libertad con que el traductor cambia con frecuencia la forma en que se expresa el texto original:

He told her, that, while prifoner to the infidels, he had dreamed that his daughter, of whom he had learned no news lince his captivity, was detained in a caftle, where the was in danger of the molt dreadful misfortunes [...] [p. 130]

Pendant que j'étois prilonnier chez les Infidèles, lui dit-il, je longeai que ma fille, dont je n'avois reçu aucune nouvelle depuis ma captivité, étoit détenue dans un Château, où elle étoit en danger d'éprouver les plus grands malheurs [...] [p. 54-55 (II)]

Podemos concluir, con respecto al nivel morfosintáctico, que la traducción persigue la naturalidad en la lengua de llegada, si bien en ocasiones el traductor se permite ciertas licencias para reformular el texto meta y se pierden determinados efectos estilísticos.

\subsubsection{Nivel léxico-semántico}

En este nivel de la lengua, englobaremos todas aquellas técnicas y errores que afectan no solo al léxico, sino también al sentido y significado de los textos original y meta. Al igual que en el nivel morfosintáctico, es frecuente el uso de la técnica de modulación, que se utiliza para producir un 
cambio de punto de vista a través del léxico. Así, por ejemplo, en el siguiente fragmento, pueden observarse dos casos de modulación en los que se cambia el punto de vista, aunque respetando el sentido original. En el primer caso, se sustituye inspired writings (que puede traducirse como "obras maestras», por ejemplo) por écrivains sacrés («escritores consagrados»), cambiando el foco de atención de la obra al autor, aunque sin variaciones de sentido importantes. En el segundo caso, se sustituye never lose light of their human character («no pierden su carácter humano») por conservent toujours le caractère de l'humanité ("conservan siempre su carácter humano»), convirtiendo la oración negativa en afirmativa.

He had oblerved, that in all infpired writings, the perlonages under the difpenfation of miracles and witnelles to the molt ftupendous phenomena, never lole light of their human character: whereas in the productions of romantic ftory, an improbable event never fails to be attended by an abfurd dialogue. [Preface, p. XV]

II a oblervé que chez les Écrivains lacrés, les Acteurs en faveur delquels les miracles s'opèrent, \& qui lont témoins des phénomènes les plus furprenans, confervent toujours le caractère de l'humanité, au lieu que dans les Romans, de pareils événemens ne manquent jamais d'être luivis d'un dialogue abfurde [Préface, p. VIII-IX]

Otra técnica que se utiliza también con bastante frecuencia en el nivel léxico-semántico es la amplificación, en la que, de acuerdo con Hurtado Albir (2011: 269), "se introducen precisiones no formuladas en el texto original: informaciones, paráfrasis explicativas, notas del traductor, etc.». Por lo tanto, en el texto en francés se utiliza con frecuencia esta técnica para explicitar elementos de información implícitos en el texto original y realizar paráfrasis y reformulaciones por motivos estilísticos o porque la lengua de llegada así lo requiere.

En algunos casos, como en el siguiente ejemplo, la técnica se asemeja a la ampliación lingüística, puesto que se añaden o explicitan elementos lingüísticos, aunque sin que varíe significativamente el sentido de la oración:

I can forget injuries, but never benefits [p. 159]

Je puis oublier les injures qu'on m'a faites, mais je n'oublie jamais les lervices qu'on m'a rendus [p. 87 (II)]

Sin embargo, también pueden encontrarse fragmentos en los que se producen paráfrasis, se reformula 0 se introducen precisiones no formuladas (implícita ni explícitamente) en el texto original, como ocurre en 
el siguiente caso. De este modo, mientras que el texto original puede traducirse como "contuvo los anhelos de su corazón y ni siquiera osó ceder a la compasión", el texto meta ha recurrido al uso de paráfrasis y a la adición de información, pudiendo traducirse del siguiente modo: «se esforzó por reprimir los sentimientos de compasión que comenzaron a crecer en su corazón; extinguió hasta el más leve resto de piedad que pudiera haber albergado». Por tanto, en la traducción se recurre a la amplificación para expresarlo de un modo más extenso y con más precisiones, lo que podría considerarse como un error de adición o hipertraducción, si bien consideramos que el significado no se altera significativamente:

[...] he curbed the yearnings of his heart, and did not dare to lean even towards pity [p. 45]

[...] il s'efforça de réprimer les lentimens de compalfion qui commençoient à s'élever dans lon coeur; il éteignit jufqu'aux moindres reltes de pitié qui pouvoient y être demeurés [...] [p. 51 (I)]

Además de la amplificación, se observa también el uso de la técnica contraria, la elisión, que consiste en la no formulación o implicitación de elementos de información presentes en el texto original, en aras de conseguir una mayor concisión o porque se consideran innecesarios en la lengua de llegada, sin llegar a constituir un error puesto que no afectan al sentido del texto. Así, en el siguiente fragmento, se sintetizan y obvian elementos de información al englobar the humour of the grave-diggers, the fooleries of Polonius and the clumsy jests of the Roman citizens («el humor de los sepultureros, las tonterías de Polonius y las burdas mofas de los ciudadanos romanos") como les bouffonneries des Fossoyeurs, de Polonius, et des Citoyens Romains («las tonterías de los enterradores, de Polonius y de los ciudadanos romanos»), asemejándose también a la técnica de compresión lingüística:

Let me ask if his tragedies of Hamlet and Julius Cælar would not lole a confiderable thare of their fpirit and wonderful beauties, if the humour of the grave-diggers, the fooleries of Polonius, and the clumly jerts of the Roman citizens were omitted, or veiled in heroics? [Preface, p. XVII]

Je demande fi les Tragédies d'Hamlet \& de Jule-Célar ne perdroient pas une partie de leurs beautés, li l'on en retranchoit les bouffonneries des Folloyeurs, de Polonius, \& des Citoyens Romains, \& qu'on les fit parler d'un ton héroïque ? [Préface, p. XII]

Finalmente, y en casos más puntuales, se utilizan técnicas como la generalización o la particularización, según se emplee un término más 
general o concreto que en el texto original. Así, por ejemplo, en la página 37 del texto original, se sustituye el término goblin (criatura mitológica malévola de apariencia similar a la de un duende) por esprit [pág. 42 (I) del texto meta], más general. Por otro lado, también pueden encontrarse algunos ejemplos de particularización, como ocurre con el término jewel que aparece en la página 170 del texto original, que se sustituye en francés como bague («anillo») [pág. 100 (II)].

Al margen de las técnicas de traducción señaladas, también pueden señalarse numerosos errores en este nivel, que se producen principalmente como resultado de las licencias que se permite el traductor para reformular o parafrasear el texto original. De entre todos ellos, el error que se produce con más frecuencia es la omisión, es decir, la eliminación injustificada de elementos de sentido o efectos estilísticos presentes en el texto original (Hurtado Albir, 2011: 291). En la mayoría de casos, estas omisiones afectan solo a la eliminación de palabras o elementos de información en la lengua de llegada, como ocurre en este fragmento:

Yet recollecting himfelf, with a mixture of grace and humility, he difengaged himfelf from Manfred's gripe, and then with an obeilance, which difcovered more jealouly of innocence, than difmay; he afked, with refpect, of what he was guilty! [p. 9]

Cependant, ayant un peu repris les lens, il le débarralfa comme il put de les mains, \& lui demanda d'un ton relpectueux quelle faute il avoit commile? [p. $10(\mathrm{I})]$

No obstante, también pueden encontrarse casos en que la omisión afecta a oraciones completas:

The fervant, who had not ftaid long enough to have crofled the court to Conrad's apartment, came running back breathlels, in a frantick manner, his eyes flaring, and foaming at the mouth. He laid nothing, but pointed to the court. The company were Itruck with terror and amazement [p. 3]

À peine avoit-il eu le temps de traverlser la cour pour le rendre à l'appartement de Conrad, qu'il revint lur les pas tout elfouflé \& hors d'haleine, le regard effaré \& la bouche écumante comme un frénétique [p. 3-4 (I)]

Aunque en la mayoría de casos estas omisiones no afectan significativamente al argumento y discurso narrativo (a pesar de ser licencias injustificadas que se permite el traductor), en ocasiones se obvian elementos de información significativos para la comprensión del texto 
original y que alteran el efecto en el texto meta. Así, por ejemplo, en el texto meta se omite el lugar de la muerte de Alfonso (in the Holy Land, es decir, en Tierra Santa), lo cual impide situar cronológicamente el relato en las Cruzadas:

Alfonso, their predeceffor dying childlefs in the Holy Land, bequeathed his eftates to my grandfather Don Ricardo [...] [p. 103]

Alphonse leur prédécelfeur étant mort lans enfans, lailfa les États à mon aïeul Don Richard [...] [p. 23 (II)]

Dejando de lado el error de omisión, pueden encontrarse también numerosos errores de adición, que responden también a las licencias que se permite el traductor para transformar o reformular el texto, aunque en la mayoría de casos no se altera significativamente el sentido del texto. En el siguiente fragmento, se añaden elementos de información que no están presentes en el texto original, ya que se especifican los métodos utilizados por el monje para apaciguar la ira del tirano a los que se hace alusión en el texto original (he left no method untried to soften the tyrant's rage). En francés, se interpreta como «no se privó de lágrimas ni de oraciones para apaciguar al tirano":

He accused himfelf in the bittereft terms for his indilcretion, endeavoured to difculpate the youth, and left no method untried to loften the tyrant's rage [p. 81]

II s'accula dans les termes les plus forts, de lon indifcrétion, s'efforça de difculper le jeune homme, \& n'épargna ni les larmes, ni les prières pour appailer le Tyran [p. 95 (I)]

En otros casos, las adiciones no afectan únicamente al estilo, sino que incluyen precisiones que no aparecen en el texto original ni explícita ni implícitamente, como ocurre en el siguiente caso:

May heaven grant thy every wilh, molt excellent Princels! faid Theodore retiring. Jerome frowned. [p. 161]

Veuille le Ciel accomplir vos louhaits, Princelle vertueufe, lui dit Théodore en fe retirant. Jérôme fronça les lourcils, \& parut fâché de ce que lon fils venoit de dire. [p. 89 (II)]

Por otra parte, cabe señalar también numerosos errores de sentido, que pueden catalogarse como falsos sentidos o contrasentidos, en función de la gravedad. Por lo que respecta al falso sentido, consiste en una «mala 
apreciación del sentido de una palabra o de un enunciado en un contexto dado, sin llegar a causar contrasentido o sin sentido" (Hurtado Albir, 2011: 291).A veces se deben, en efecto, a malas apreciaciones del sentido, que incurren en alteraciones que no llegan a cambiar radicalmente el sentido o a traicionar la obra original. En otros casos, el traductor se permite ciertas licencias para reformular el texto original, de modo que, al hacerlo, se altera ligeramente el sentido. En el siguiente fragmento, por ejemplo, se produce un falso sentido al traducir el texto original («Un murmullo de aprobación se elevó gradualmente entre los presentes») como: "Todos los presentes aplaudieron su discurso», añadiendo más énfasis a la situación descrita:

A murmur of approbation gently arole from the audience [p. 139]

Toute l'alfemblé applaudit à fon difcours [p. 65 (II)]

No obstante, sí resultan más graves los contrasentidos, que tienen también una incidencia notable en el texto meta. De este modo, se traducen incorrectamente determinados fragmentos, por lo que el sentido cambia radicalmente con respecto al original y se le da un sentido opuesto o totalmente erróneo. Este error se produce con mayor frecuencia en el prólogo, donde se traiciona el pensamiento del autor y lo expresado en el texto original. Así, cuando Walpole habla sobre sus pretensiones con respecto a la creación de su novela, afirma lo siguiente:

It was an attempt to blend the two kinds of Romance, the ancient and the modern. [...]The author of the following pages thought it porlible to reconcile the two kinds. [Preface, p. XIV]

Sin embargo, en el texto meta se altera el sentido puesto que, en el texto original, se argumenta que la novela constituye un intento de unir los dos tipos de romance o novela, el antiguo y el nuevo. Sin embargo, en el texto meta se comienza diciendo que no hay nada tan difícil como unir estos dos géneros, añadiendo un matiz que no está presente en el original. Asimismo, se produce un contrasentido porque se atribuye a thought it possible to reconcile («creyó que era posible reconciliar») un sentido erróneo al traducirlo como s'est efforcé de concilier («se ha esforzado por reconciliar»), puesto que en el texto original no se indica que se haya conseguido reconciliar los dos géneros, sino que se creyó posible, mientras que en el texto meta el uso del verbo 'esforzarse' implica que se llegó a conciliar estos dos géneros con esfuerzo. 
Rien n'elt li difficile que de concilier enfemble les deux genres de Romans, je veux dire, l'ancien et le moderne. [...] L'Auteur s'elt efforcé de concilier les deux genres. [Préface, p. VII]

Por otra parte, en ocasiones se confunden los personajes a los que se alude realmente en el texto original, cambiando así el sentido e incurriendo en contrasentidos, por lo que la formulación en la lengua de llegada puede llegar a resultar absurda.En el siguiente fragmento, por ejemplo, se produce un error al cambiar la referencia a my friend [Isabella] («mi amiga») por mon frère (mi hermano).

Bianca, faid the Princels, I do not allow you to mention my friend difreipectfully. Ifabella is of a chearful difpolition, but her foul is pure as virtue itfelf. [p. 52]

Parlez avec plus de refpect de mon frère, lui dit la Princelle. Ifabelle aime à badiner, mais lon ame elt aufli pure que la vertu même [p. 60 (I)]

Finalmente, puede señalarse también el error de hipertraducción que afecta de forma generalizada al conjunto de la obra, y que consiste, de acuerdo con Delisle, y como recoge Hurtado Albir (2011: 291), en «elegir sistemáticamente entre varias posibilidades de traducción aceptables, traducción literal incluida, el giro cuya forma se aleja más de la expresión original». A raíz del análisis comparativo de ambas obras, se ha podido comprobar que el traductor francés a menudo utiliza una opción de traducción alejada del texto original. Aunque en estos casos el sentido no se altera significativamente, pues se trata de una reformulación o paráfrasis de lo expresado en la obra original, consideramos que la frecuencia con la que se produce permite considerarlo un error de traducción que comete Eidous para otorgar al texto efectos estilísticos ausentes en el texto de partida o cambiar el estilo de la obra original para adaptarlo a lo que él considera más apropiado para los receptores franceses.

Un ejemplo de este error puede observarse en el siguiente fragmento, donde se produce además una ampliación lingüística al añadir más elementos de información:

The Princeffes were all attention and anxiety [p. 148]

Ces paroles attirèrent l'attention des Princelfes, \& leur causèrent les plus vives inquiétudes [p. 74 (II)]

Otro caso de hipertraducción puede encontrarse también en el siguiente extracto, en el que puede observarse cómo el traductor ha optado 
por una traducción totalmente alejada del original, en la que incluso varía el sentido. Así, mientras que en inglés Isabella manifiesta que «la pureza de vuestro propio corazón os impide ver la depravación de otros», en el texto meta las palabras que dice son: «las personas que tienen buen corazón juzgan a las otras como a ellas mismas». Por tanto, pasa de ser una aseveración sobre el carácter de Hippolita a una generalización sobre las personas de buen corazón:

Alas! faid Ifabella, the purity of your own heart prevents your leeing the depravity of others [p. 149]

Hélas! lui dit Ilabelle, les perronnes qui ont le coeur bon, jugent des autres par eux-mêmes [p. 75 (II)]

En definitiva, el nivel léxico-semántico se caracteriza, en general, por la libertad que se toma el traductor para traducir el texto original, lo que puede constatarse por medio del uso frecuente de técnicas como la modulación o la amplificación. No obstante, a pesar de que el texto meta resulta natural en la lengua de llegada, a menudo se incurren en numerosos errores de sentido (falsos sentidos y contrasentidos), que alteran el significado del texto, así como a numerosos errores que se producen como resultado de la libertad que se permite el traductor para transformar el texto, como adiciones, omisiones e hipertraducciones.

\subsubsection{Nivel pragmático-cultural}

En este nivel, englobamos todo aquello que se refiere a la comprensión del texto por parte del receptor en función de la finalidad del texto, el contexto en que se incluye y la cultura de la que procede. Por tanto, este nivel abarca no solo aquellos aspectos lingüísticos relacionados con la función del texto meta y el contexto comunicativo en el que tiene lugar, sino también las cuestiones relacionadas con la traducción de referentes culturales o históricos en la lengua de llegada.

Por lo que respecta de forma más concreta a la traducción de nombres propios, en la mayoría de casos se recurre a la adaptación (ya sea mediante equivalentes acuñados o por adaptación gráfica y fonética al francés) que aparecen originalmente italianizados en su mayoría, por lo que se pierde el efecto "exotizante» que posee el texto original. De este modo, antropónimos como Matilda, Isabella, Alfonso the Good, Bianca, Jerome, Andrea, Ricardo o Victoria se traducen como Mathilde, Isabelle, Alphonse le Bon, Blanche, Jérôme, André, Richard o Victoire; de manera similar, los topónimos como Vicenza o Otranto aparecen traducidos como Vicenceo Otrante. 
Sin embargo, esta técnica no se lleva a cabo en todos los nombres, puesto que algunos, debido a la imposibilidad de adaptarlos gráfica y fonéticamente o bien por decisión del traductor, se mantienen como en la versión original. Es lo que ocurre con el nombre de los sirvientes Diego, Lopez y Donna Rosara, el nombre del hermano Martelli o de la referencia a la princesa Sanchia d'Arragon (traducido como Sanchia of Arragon), así como del topónimo del condado de Falconara, que se mantienen del mismo modo en francés. Por tanto, la adaptación se limita a la adaptación gráfica y fonética en la lengua de llegada pero, en los casos en que no es posible, se mantienen los nombres originales.

Otro aspecto que debe señalarse en el texto meta que afecta al nivel pragmático-cultural es la traducción al francés de la segunda persona, pues en inglés la forma you (o el pronombre personal arcaico thou) se utiliza en todos los casos, independientemente de la distancia que separe al emisor del receptor o de su condición social o jerárquica. Sin embargo, en francés existen dos posibilidades para la segunda persona del singular: tu o vous, que se utiliza como forma de cortesía, de forma similar al usted español. Por lo tanto, en la traducción se emplean distintas formas en función del personaje que intervenga y sus destinatarios.

En el siguiente fragmento, por ejemplo, se produce una interacción entre Manfred y dos de sus sirvientes, Diego y Jaquez. Este último se dirige a su señor como my Lord («Monseigneur», en francés) y your Highness («votre Altesse»), por lo que el traductor ha recurrido a la forma de cortesía vous para que el criado se dirija a Manfred (como puede comprobarse por el uso de posesivos como votre o vos). Por lo que respecta a Manfred, este habla a su sirviente utilizando la forma de segunda persona del singular ( $t u)$, lo que nos parece más acertado que vous, ya que se trata de sus sirvientes y están en una posición jerárquica inferior (teniendo en cuenta, además, la actitud tiránica de Manfred hacia sus subordinados). Sin embargo, consideramos que se produce una incoherencia, pues al principio del fragmento se dirige a otro sirviente y le dice que se retire utilizando la forma vous (Retirez-vous, Diego), mientras que en el texto original se muestra mucho más impositivo y descortés al decir out of my sight («fuera de mi vista»):

Out of my fight, Diego! and thou Jaquez, tell me in one word, art thou lober? art thou raving? thou walt wont to have a lome lenle: has the other lot frightened himfelf and thee too! fpeak; what is it he fancies he has leen? Why, my Lord, replied Jaquez trembling, I was going to tell your Highnels that fince the calamitous misfortune of my young Lord, God reft his precious loul! Not one of us your Highnels's faithful lervants, indeed we are, my Lord, though poor men [...] [p. 36-37] 
Retirez-vous, Diego. Et toi, Jacques, dis-moi, es-tu dans ton bon lens? Rêves-tu? Tu m'as toujours paru allez lenfé; cet autre lot t'a-t-il aulfi effrayé? Parle, qu'as-tu vu ? Pourquoi, Monleigneur, reprit Jaques en tremblant, j'allois dire à votre Altelle, que depuis l'accident qui elt arrivé à mon jeune Seigneur, à qui Dieu falle paix, aucun de vos fidelles lerviteurs, nous lommes tels, bien que pauvres [...] [p. 41 (I)]

Sin embargo, esta incoherencia con respecto al trato de los sirvientes se manifiesta en más ocasiones, como en la página 40 , por ejemplo, en la que se dirige a Jaquez en los siguientes términos: Vous, Jacques, répondez-moi; car votre camarade paroît avoir l'elprit plus égaré que vous. Consideramos, por tanto, que la forma tu es más adecuada, teniendo en cuenta el carácter del personaje y su relación con los demás. No obstante, sería conveniente que se empleara siempre la misma forma de tratamiento para mantener la coherencia en la narración ${ }^{17}$.

No obstante, en relación con el uso de las personas gramaticales, sí consideramos erróneo que el traductor se permita la licencia de utilizar la primera persona del singular o del plural en algunos casos en el discurso del narrador, puesto que en el texto original siempre se expresa en tercera persona, sin intervenir en el relato, como un narrador omnisciente. Sin embargo, aunque en el texto meta también se suele utilizar la narración en tercera persona, pueden encontrarse casos, como el que se muestra aquí (que contiene, además, un error de adición), en que el texto en francés recurre a la primera persona del plural, de modo que el narrador interviene en el relato:

Manfred was now returning from the vault, attended by a pealant and a few of his fervants whom he had obliged to accompany him [p. 43]

Manfred lortit du louterrain où nous l'avons laillé, accompagné du Paylan \& de quelques domeltiques qu'il avoit obligés à le fuivre [p. 49 (I)]

En otros casos, el narrador emplea también la primera persona del singular, como en el siguiente fragmento: Manfred, après avoir fait les réflexions que je viens de dire, parla au Héraut en ces termes: Retournez vers votre Maître [...] [p. 11 (II)]. Sin embargo, en el texto original no se produce tal intervención del narrador, como puede observarse: Herald, laid Manfred, as loon as he had digelted thele reflections, return to thy malter [...] [p. 93]. Consideramos, por tanto, que se trata de un error de traducción,

\footnotetext{
${ }^{17}$ Asimismo, puede constatarse cómo el traductor decide emplear la forma de cortesía entre los nobles para dirigirse unos a otros, así como para tratar al padre Jerome, debido al respeto que se profesa a los miembros de la Iglesia.
} 
puesto que traiciona la obra original al no mantener la narración en tercera persona e involucrarse en el relato como un personaje más. Asimismo, resta verosimilitud al relato, puesto que se pierde el efecto de narración de hechos remotos.

Asimismo, consideramos que la libertad que se permite el traductor incurre en otros errores relacionados con el nivel pragmático-cultural, como su decisión de modificar pasajes escritos con un estilo indirecto para convertirlos en estilo directo y convertir en intervenciones de determinados personajes lo que en el texto original aparece referido en tercera persona en la narración, puesto que supone una traición y alteración del texto original. Es lo que ocurre en el siguiente fragmento donde, si bien no se altera el sentido original, se trata de un cambio innecesario:

He told her, that, while prifoner to the infidels, he had dreamed that his daughter, of whom he had learned no news lince his captivity, was detained in a caltle, where the was in danger of the molt dreadful misfortunes [...] [p. 130]

Pendant que j'étois prilonnier chez les Infidèles, lui dit-il, je longeai que ma fille, dont je n'avois reçu aucune nouvelle depuis ma captivité, étoit détenue dans un Château, où elle étoit en danger d'éprouver les plus grands malheurs [...] [p. 54-55 (II)]

Finalmente, en el nivel pragmático-cultural pueden señalarse también frecuentes errores de omisión en el prólogo, como ocurre con el soneto que Walpole dedica a su amiga Mary Lady Coke (p. XI). Consideramos que esto puede deberse a la decisión del traductor de omitirlo en francés puesto que estaba dedicado a una aristócrata inglesa amiga de Walpole y, por lo tanto, no tenía relevancia en la traducción para los receptores franceses. Sin embargo, es este soneto el que revela la identidad del autor original, ya que aparece firmado por las iniciales «H. W.».

Asimismo, y aunque ya se han señalado otros errores de omisión en el nivel léxico-semántico, también se producen errores de omisión que afectan al nivel pragmático-cultural en el prólogo, sobre todo en lo que respecta a la opinión que manifiesta Walpole sobre Voltaire. Así, por ejemplo, en el siguiente fragmento, el traductor omite el inciso que hace el autor para mostrar su opinión sobre la obra de Voltaire. Consideramos que se trata de un error de omisión en el nivel pragmático-cultural porque, por una parte, se debe a una decisión del traductor de eliminar elementos que no considera necesarios (y que podría haber incluido precisando que dichos argumentos no son suyos) y, por otra parte, esta decisión puede afectar al nivel pragmático al entenderse de otra manera por parte del receptor 
francés (podría interpretarse, en este sentido, como una crítica del inglés hacia el escritor francés menos respetuosa de lo que realmente es):

In the preface to his Enfant Prodigue, that exquilite piece of which I declare my admiration, and which, Thould I live twenty years longer, I truft I Thall never attempt to ridicule, he has thele words, ipeaking of Comedy. [Preface, p. XIX]

Voici ce qu'il dit de la Comédie dans la Préface de l'Enfant Prodigue. [Préface, p. XIII]

Al igual que ocurre con el ejemplo anterior, en esta oración el traductor también omite las referencias positivas que Walpole hace a Voltaire, a pesar de que esté haciendo una crítica a sus palabras. Sin embargo, en el texto meta la crítica es más tenaz porque se omiten las apreciaciones del autor:

Thefe paffages were indubitably the genuine fentiments of that great writer [Preface, p. XX]

Ces palfages lont donc fûrement de lui [Préface, p. XVIII]

En definitiva, y al igual que ocurría con los niveles anteriores, el nivel pragmático-cultural se caracteriza por la libertad en la traducción y la voluntad del traductor de "afrancesar» el texto o transformarlo utilizando un estilo diferente.

\section{CONCLUSIONES}

En este apartado, presentaremos las conclusiones que hemos extraído a raíz del análisis traductológico de la obra The Castle of Otranto y su versión al francés. No obstante, puesto que ya hemos manifestado algunas conclusiones con respecto al análisis de traducción, nos limitaremos a realizar una recapitulación de los resultados de nuestro trabajo y estableceremos unas conclusiones globales sobre el análisis traductológico de ambas versiones.

En primer lugar, podemos constatar que The Castle of Otrantoes una obra que, a pesar de las duras críticas que recibió en su época por la transgresión a los modelos estéticos literarios del periodo ilustrado, fue bien acogida por el público inglés, si bien su popularidad aumentó posteriormente gracias a la publicación de otras novelas góticas como las de Ann Radcliffe o Matthew Lewis. No obstante, independientemente de la calidad de la obra original que, sin duda, sería superada con creces por otros autores en las décadas posteriores, la aportación de Walpole a la 
literatura contribuyó al desarrollo de un nuevo subgénero literario que no solo dio origen a una nueva corriente estética, sino que continuó influyendo en mayor o menor medida en los siglos posteriores con nuevos subgéneros literarios, como la novela policíaca o la novela negra. En Francia, sin embargo, la novela no cosechó un gran éxito debido, por una parte, a que se trató de un género demasiado novedoso para el público francés, aunque los acontecimientos de la Revolución francesa y el desarrollo posterior de la novela gótica en la década de 1790 gracias a las obras de Lewis y Radcliffe contribuyeron a una mejor consideración de la obra de Walpole.

Por lo que respecta al análisis traductológico llevado a cabo tanto del prólogo a la segunda edición como de la novela propiamente dicha, el análisis de las técnicas de traducción revela el uso frecuente de técnicas de reformulación como la transposición y la modulación, así como amplificaciones, elisiones, ampliaciones y compresiones lingüísticas. Desde nuestro punto de vista, el uso de estas técnicas responde a la búsqueda de naturalidad en la lengua de llegada y a la intención de reflejar un estilo apropiado en francés. De este modo, técnicas como la amplificación, la elisión o la ampliación y compresión lingüísticas se utilizan para añadir elementos que el traductor considera pertinentes $u$ omitir aquellos que considera obvios e innecesarios. Por otro lado, la frecuencia de uso de técnicas como la amplificación y modulación parece responder también a la decisión del traductor de introducir precisiones no formuladas en el texto original o reformularlo, bien por motivos estilísticos o para que resulte más natural en la lengua de llegada.

Por lo tanto, el empleo de estas técnicas de traducción, que permiten al traductor distanciarse de una traducción literal y reformular en ocasiones el texto de partida, acercan el texto meta al método interpretativocomunicativo que, de acuerdo con la clasificación propuesta por Hurtado Albir (2011: 252), es aquel que se centra en la «comprensión y reexpresión del sentido del texto original conservando la traducción la misma finalidad que el original» (Hurtado Albir, 2011:252). No obstante, la libertad y licencias que se permite el traductor a la hora de traducir permiten establecer también algunas similitudes con el método libre que, de acuerdo con Hurtado Albir (2011: 252), es aquel que «no persigue transmitir el mismo sentido que el texto original aunque mantiene funciones similares y la misma información». Sin embargo, puesto que la libertad a la hora de traducir y distanciarse del texto original no afecta al conjunto del relato, sino fundamentalmente a determinados fragmentos y, particularmente, al nivel léxico-semántico, no consideramos que se trate de una traducción libre, aunque sí se aleja de la traducción literal al reformular el texto original para adecuarlo al estilo y naturalidad de la lengua de llegada. 
No obstante, el distanciamiento del texto original o las continuas reformulaciones y modificaciones en el plano léxico y morfosintáctico que lleva a cabo el traductor incurren con bastante frecuencia en errores de traducción, sobre todo en el nivel léxico-semántico, donde se producen numerosas adiciones, omisiones injustificadas, así como errores de sentido como falsos sentidos y contrasentidos (según la gravedad de los mismos).

Por lo que respecta a las omisiones, se eliminan injustificadamente elementos de información (aclaraciones o incisos descriptivos, en su mayoría) que, aunque por lo general no afectan significativamente al sentido de la obra en su conjunto, responden a una decisión del traductor para mejorar el relato u obviar aquello que considera irrelevante, por lo que constituyen un error y una traición al texto original. En otros casos, sin embargo, sí se prescinde de oraciones completas, que afectan no solo a descripciones sino a acciones, por lo que se altera el discurso narrativo. Asimismo, en el prólogo se omiten fragmentos en los que el autor original muestra su opinión (sobre todo, en lo que respecta a las opiniones favorables de Walpole con respecto a Voltaire), y que el traductor omite injustificadamente, de modo que el receptor francés percibe una crítica más dura que el receptor inglés. Por otro lado, se producen también continuas adiciones en el nivel léxico-semántico, bien por motivos estilísticos o porque el traductor considera pertinente introducir precisiones no formuladas en el texto original, aunque no aparezcan implícita ni explícitamente, por lo que se trata de adiciones injustificadas.

Finalmente, por lo que respecta a los errores de sentido (contrasentidos y falsos sentidos, en función de la gravedad), aunque no alteran tampoco de manera significativa el conjunto del relato, no dejan de ser errores que cambian el sentido del texto original y pueden producir un efecto distinto en el receptor, bien porque lo confundan o porque contribuyan a una alteración de la percepción de los personajes y los acontecimientos que se producen. Aunque en algunos casos estos errores de sentido parecen responder a errores no intencionados del traductor, provocados por errores de comprensión, consideramos que, en otros muchos casos, se deben a las continuas modulaciones y reformulaciones que se producen, que dan lugar a variaciones en el sentido.

Asimismo, y en relación con estos errores, cabe destacar los errores que se producen de forma generalizada en toda la traducción y que hemos catalogado como «hipertraducciones», es decir, aquellos que se producen cuando el traductor escoge deliberada y sistemáticamente la opción de traducción más alejada del texto original. Desde nuestro punto de vista, estos errores se producen con frecuencia por motivos estilísticos, al decidir el traductor que el texto original puede expresarse de otra manera más adecuada en el texto meta, de modo que, en cierto sentido, traiciona la obra 
original, al intentar cambiar su estilo por otro que el traductor considera más adecuado para los receptores franceses.

Por último, puede afirmarse que esta libertad y alejamiento del texto original se manifiesta también en otros aspectos, como en la decisión de adaptar los nombres propios a la lengua de llegada, privando de este modo al texto meta del carácter "exotizante» de la obra original, que utilizaba nombres italianizados para situar la novela en un lugar remoto. En francés, sin embargo, se adaptan gráfica y fonéticamente los nombres (no en todos los casos, sin embargo, pues en algunos nombres no es posible), de forma que se pierde ese carácter extranjerizante. Del mismo modo, la traducción al francés no conserva el estilo arcaizante y literario del texto original, por lo que también se pierde el efecto que ayuda a situar el relato en un pasado lejano. A esta pérdida de matices en la situación del contexto espaciotemporal contribuye también el empleo de la primera persona en algunos casos para enunciar la narración, puesto que en el texto original el narrador siempre se expresa en tercera persona, lo que contribuye además a situar el relato en una época remota y a que resulte misterioso.

En definitiva, y a raíz del análisis llevado a cabo, podemos concluir que se trata de una traducción que respeta la función y el género textual de la obra original, gramaticalmente correcta y con un estilo natural en la lengua de llegada. No obstante, en ocasiones se aleja demasiado del texto original incurriendo en errores de hipertraducción, así como en omisiones, adiciones y errores de sentido, y se pierden numerosos matices que contribuyen a recrear el efecto misterioso de unos acontecimientos que se sitúan en un pasado remoto y un lugar lejano. En efecto, consideramos que la traducción es correcta en general, pero a menudo carece de exactitud y no mantiene los efectos estilísticos del texto original. Asimismo, cabe recordar que el propio Walpole, como hemos recogido con anterioridad, consideró que se trataba de una traducción de mala calidad (Killen, 1984: 74). No obstante, a pesar de que la calidad de la traducción de Eidous pueda resultar cuestionable, no podemos dejar de lado la situación de la traducción en el siglo XVIII y las corrientes y políticas de traducción predominantes en este siglo. Las traducciones de esta época se caracterizaron, por lo general, por su falta de fidelidad al texto original, recurriendo con frecuencia a la adaptación y a la reescritura, de ahí que se conozca este estilo de traducción como las belles infidèles.

Aunque ya hemos mencionado anteriormente las características de esta corriente de traducción, resulta interesante la aportación que realizan Alberdi y Arregui (2009: 81-130) al respecto de las políticas de traducción del siglo XVIII. Como señalan las autoras, esta belleza infiel propia de las traducciones del siglo XVIII, motivada por el deseo de los traductores de adaptar el texto original al gusto francés, se caracterizaba a menudo por la 
omisión de todo aquello que el traductor consideraba redundante, demasiado descriptivo o, simplemente, que no guardaba estrecha relación con el tema central de la obra, ya que el público francés achacaba con frecuencia a los ingleses las continuas digresiones y la infracción de las unidades de acción al dejarse llevar por la imaginación en lugar de ceñirse a un orden lógico (Alberdi y Arregui, 2009: 111). En efecto, como se ha podido comprobar en el análisis traductológico, las omisiones constituyen el error que se produce con más frecuencia, lo que puede reflejar, en este sentido, la decisión del traductor de eliminar todo aquello que considera superfluo en la narración.

Por otra parte, y aunque no formaba parte de nuestros objetivos principales, la realización del análisis traductológico y el uso de la clasificación propuesta por Delisle para la categorización de los errores de traducción (recogida en Hurtado Albir, 2011: 291) ha puesto de relieve, desde nuestro punto de vista, algunos puntos débiles de esta clasificación. A este respecto, cabe señalar que en ocasiones resulta complicado distinguir entre contrasentidos y falsos sentidos, ya que la frontera entre la mala apreciación del sentido de un enunciado (falso sentido) y la atribución de un sentido totalmente erróneo (contrasentido) resulta difusa y, a menudo, se ve sujeta al propio criterio de la persona que evalúa la traducción, según la gravedad del error de sentido. Hurtado Albir (2011: 292), en efecto, señala ya las críticas que ha recibido esta clasificación por la inexistencia de fronteras nítidas entre las diferentes categorías o la falta de explicación, además de limitarse a la tipificación de errores en comparación con el texto original sin argumentar las causas que los motivan (aunque la autora indica que, hasta el momento, resulta difícil no recurrir a esta categorización para evaluar las traducciones).

Por último, y una vez expuestas las conclusiones a las que hemos llegado tras realizar el análisis traductológico, podemos afirmar que este estudio ha servido para aplicar nuevos modelos de análisis traductológicos a la literatura comparada, de modo que puedan evaluarse las traducciones no solo desde un punto de vista filológico, sino también lingüístico, atendiendo al producto final y a la descripción comparativa de las versiones original y traducida. No obstante, consideramos que, en futuros estudios, el presente trabajo podría mejorarse analizando varias traducciones al francés, llevadas a cabo en diferentes épocas y por distintos traductores, así como incluir el análisis de traducciones a otros idiomas como el español. Por otra parte, este estudio comparativo y descriptivo podría verse enriquecido con la inclusión del análisis de otras obras pertenecientes al género gótico, para comprobar también la relación entre la calidad de la traducción y su recepción, por un lado, así como para determinar si se sigue el mismo método traductor y se emplean técnicas de traducción similares, de modo 
que podamos llegar a conclusiones más sólidas y globales sobre la traducción de la literatura gótica en el siglo XVIII en Francia e, incluso, en España.

\section{REFERENCIAS BIBLIOGRÁFICAS}

AlBERDI URQUIZU, Carmen; ARREGUI BARRAGÁN, Natalia, “La traducción en la Francia del siglo XVIII: nuevos modelos literarios, auge de la belleza infiel y femenina". En: Sabio Pinilla, José Antonio (ed.). La traducción en la época ilustrada (panorámicas de la traducción en el siglo XVIII). Colección Interlingua, 82. Granada: Comares, 2009, pp 81-130.

BotTING, Fred, Gothic. London: Routledge, 2008.

CARSON, James P., "Enlightenment, popular culture, and Gothic fiction". En: Richetti, John. (ed.). The Cambridge companion to eighteenth-century novel. Cambridge: University of Cambridge, 2009, pp. 254-276.

CARTER, Ronald; MCRAE, John, The Routledge history of literature in English. London: Routledge, 2006.

CONCHA, Ángeles de la, "El siglo XVIII". En: Pérez Gallego, Cándido (dir.). Historia de la literatura inglesa. Madrid: Taurus, 1988, vol. 2, pp. 8132.

ELLIS, Markman, The history of gothic fiction. Edinburgh: University of Edinburgh, 2007.

HALE, Terry, "French and German Gothic: the beginnings". En: Hogle, Jerrold $\mathrm{E}$. The Cambridge companion to gothic fiction. Cambridge: University of Cambridge, 2008, pp. 63-84.

HuRTAdo AlBIR, Amparo, Traducción y traductología: Introducción a la traductología. 5. a edición revisada. Madrid: Cátedra, 2011.

KAFKER, Frank A., "Notices sur les auteurs des dix-sept volumes de «discours» de l'Encyclopédie". En: Recherches sur Diderot et sur l'Encyclopédie, vol. 7, n.ำ 7, 1989, pp. 125-150.

Ketton-Cremer, R. W., Horace Walpole: a biography. London: Faber and Faber, 1946.

KILLEN, Alice M., Le roman terrifiant ou roman noir: de Walpole a Anne Radcliffe et son influence sur la littérature francaise jusqu'en 1840. Genève-Paris: Slatnike reprints, 1984.

LUCKHURST, Roger, "The public sphere, popular culture and the true meaning of the zombie apocalypse”. En: Glover, David y McCracken, Scott (ed.). The Cambridge companion to popular fiction. Cambridge: University of Cambridge, 2012, pp. 68-85.

LYNCH, Dreide, "Gothic fiction". En: Maxwell, Richard y Trumpener, Katie. The Cambridge companion to fiction in the Romantic period. Cambridge: Cambridge University Press, 2008, pp. 47-63. 
MICHAUD, Joseph-François; MICHAUD, Louis-Gabriel (dir.), Biographie universelle, ancienne et moderne, ou Histoire, par ordre alphabétique, de la vie publique et privée de tous les hommes qui se sont fait remarquer par leurs écrits, leurs actions, leurs talents, leurs vertus ou leurs crimes. Paris: C. Desplaces, 1855, vol. 12.

PRUNGNAUD, Joëlle, "La traduction du roman gothique anglais en France au tournant du XVIIle siècle". En: TTR: traduction, terminologie, rédaction, vol. $7, \mathrm{n}{ }^{\circ} 1,1994, \mathrm{pp} .11-46 . \mathrm{D}$

PUNTER, David, The literature of terror: a history of gothic fictions from 1765 to the present day, vol. 1. London: Longman, 1996.

SCHNEIDER, Marcel, Histoire de la littérature fantastique en France. [s. I.] Fayard, 1985.

SPACKS, Patricia Ann Meyers, Novel beginnings: experiments in eighteenthcentury English fiction. New Haven: Yale University Press, 2006.

WATT, Ian P., "Time and family in the gothic novel: The Castle of Otranto". En: Kroll, Richard. The English novel: Smollett to Austen. London: Longman, 1998, vol. 2, pp. 191-205. 